\title{
Phonon Absorption-Spectroscopy in the Presence of Strong Elastic Phonon Scattering
}

\author{
J. Mebert ${ }^{1}$, O. Koblinger ${ }^{2}, S$. Döttinger ${ }^{1}$, and W. Eisenmenger ${ }^{1}$ \\ ${ }^{1}$ Physikalisches Institut, Universität Stuttgart, Pfaffenwaldring 57, \\ D-7000 Stuttgart 80, Fed. Rep. of Germany \\ 2IBM-Deutschland, GmbH, Schönaicherstr. 220, \\ D-7030 Böblingen, Fed. Rep. of Germany
}

\section{Introduction}

Rare Barth doped crystals are known to show very aharp absorption lines in IR-absorption measurements due to 4i-intre-shell transitions of the Rare Earth dopents. The line sharpness 18 caused by screening the 4f-orbit by electrons occupying the spetials extented 5 and $5 p$ shells. Absorption lines have been found at $21.2 \mathrm{~cm}^{-1}$ and $32.8 \mathrm{~cm}^{-1}$ in $\mathrm{Fr}^{3+}$ doped $\mathrm{CaP}_{2}[1]$ and at $52 \mathrm{~cm}^{-1}$ in $\mathrm{Br}^{3+}$ doped $\mathrm{LaP}_{3}[2]$. In this energy range phonon spectroscopy is a good and useful method in absorption measurements. The predominant advantages are the very high frequency resolution of about $10 \mathrm{GHz}$ (in IR typical $30 \mathrm{cHz}$ ) and the existence of other coupling mechanisms for the 4f-intra shell transitions. In IR-spectroscops these transitions are characterized by a small oscillator atrength because they are forbidden in first order by the parity selection rule. Phonon transitions are induced by orbitlattice coupling allowing transitions without parity change.

In pulse measurements a strong elastic phonon scattering can be observed. Such elastic phonon-scattering was also published by different other authors $[3 / 4]$ in recent times. In this work we show that in the presence of a strong phonon scattering beckground absorption structures can only be well resolved by reducing semple thickness to the phonon mean free path. This mean free path can be determined by analyzing the pulse shape of $285 \mathrm{GHz}$ phonons. By reducing aample thickness to the appropriate value of $0.3 \mathrm{mn}$ the $21.2 \mathrm{~cm}^{-1}$ crystalline fleld transition in $\mathrm{CaF}_{2}: \mathrm{Fr}^{3+}$ could be evaluated with the very high resolution of $5 \mathrm{GHz}$. In experiments performed on a $1 \mathrm{~mm}$ thick $\mathrm{LaF}_{3}: \mathrm{Fr}^{3}$ sample we observed an absoption line at $14.2 \mathrm{~cm}^{-1}$ not visible in FIR absorption measurements.

\section{Phonon spectroscopg measurements at $\mathrm{CaF}_{2}: \mathrm{Fr}^{3+}$}

Phonon epectroscopy measurements with an 11 and a Sn tunneling junction as voltage tunable phonon generator and detector respectively were applied to $\mathrm{Er}^{3}$ doped Car 2

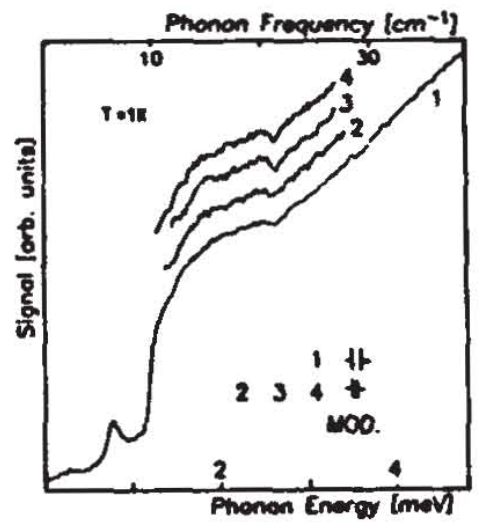
using the well known modulation technique. The basic intention was to evaluate the crystalline field absorption lines reported above. $\mathrm{Fg}_{\mathrm{g}} 1$ shows the corresponding phonon absorption spectrum. The sample thickess in this case was d = $2 \mathrm{~mm}$. At $636 \mathrm{GHz}\left(21.2 \mathrm{~cm}^{-1}\right)$ a weak, hardly resolved absorption line can be recognieed. This structure can be ascribed to the $21.2 \mathrm{~cm}^{-1}$ absorption line know from PIR measurements.

Fig. 1 Phonon absorption spectrum of $\mathrm{CaP}_{2}: \mathrm{Fr}^{3+}$ $d=2 \mathrm{~mm}$ 
In this technique superconductive Sn-tunnel junctions are used as well as phonon generator and phonon detector. The advantage of this arrangement is the possibility of investigating nonequilibrium phonon propagation at the fixed frequency of $285 \mathrm{GHz}$ coupled with a high $\mathrm{S} / \mathrm{H}$ ratio. Fig $2 \mathrm{a}, \mathrm{b}_{3}$ and $\mathrm{c}$ show the $\mathrm{Sn} / \mathrm{Sn}$ pulsemeasurements of $\mathrm{Sr}_{2}: \mathrm{Bu}_{2}{ }^{7}, \mathrm{LaF}_{3}: \mathrm{Fr}^{3}$ and $\mathrm{CaF}_{2}: \mathrm{Fr}^{3+}$ respectively.

The generator pulse width was $0.2 \mu \mathrm{s}$ in case $\mathrm{a}, 0.4 \mu \mathrm{s}$ in case $\mathrm{b}$ and $0.3 \mu \mathrm{s}$ in $\mathrm{c}$. The detector signal on the other hand extends over a range of about $10 \mu \mathrm{s}$. This large extension of the detector slgnal indicates a strong elastic scattering of the $285 \mathrm{GHz}$ phonons increasing both the pulse propegation time and the pulse width such nonequilibrium phonon propegation determined by strong elastic scattering processes is called "diffusive" phonon propagation. The essential acattering mechanisms leading to diffusive phonon propegation are mass defect scattering and scattering processes at lattice imperfections [5].

\section{The influence of strong elastic phonon scattering on phonon absorption}

$$
\text { measurements }
$$

In phonon absorption spectroscopy absorption structures are indicated by absorption and reenission of resonant phonons 1.e. elastic scattering of the resonant phonons at the absorption centers. In the presence of a strong elastic scattering background the resonant scattering at absorption centers is a weak additional effect, hardly detectable. Hy reducing the sample thickness to the elastic scattering mean free path of the phonons the elastic scattering background can be reduced and the resonant phonon scattering at absorption centers becomes resolvable. In a first order approximation the mean free phonon path in the frequency range from $200 \mathrm{GHz}$ to $1 \mathrm{THz}$ can be estimated by the mean free peth of $285 \mathrm{GHz}$ phonons.

This value can be determined by fitting the pulse measurements (Fig. 2) to an anelytic expression for the detector signal based on the diffusive equations well
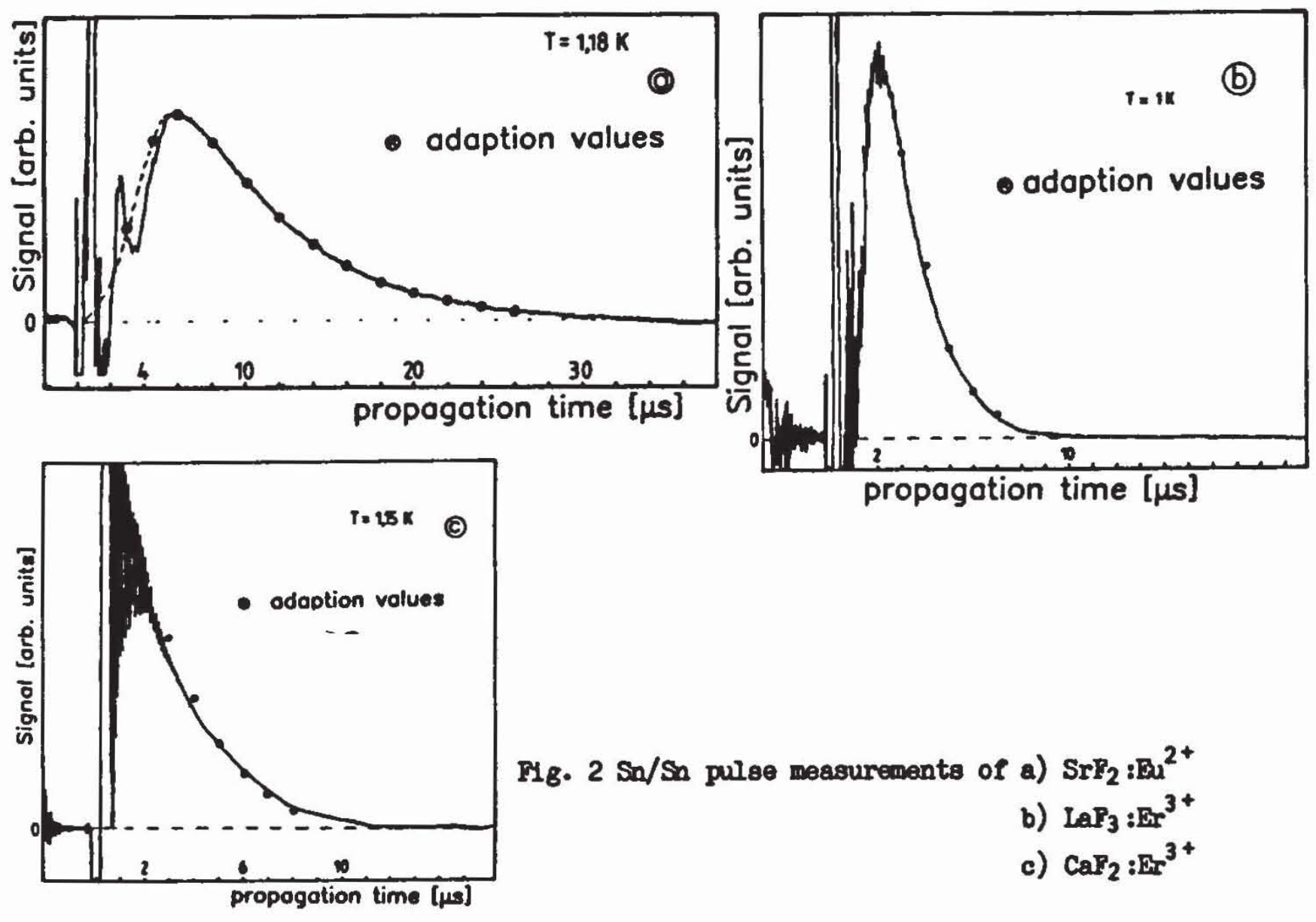

$\mathrm{Fig}_{\mathrm{g}} 2 \mathrm{Sa} / \mathrm{Sn}$ pulse measurements of a) $\mathrm{SrP}_{2}: \mathrm{Bu}^{2+}$

b) $\mathrm{LaP}_{3}: \mathrm{Fr}^{3+}$

c) $\mathrm{CaF}_{2}: \mathrm{Fr}^{3+}$ 
known from kinetic theory. The adaption values are shown in $\mathrm{Fig}_{\mathrm{g}}$. 2. The values obtained for $\lambda(285 \mathrm{GHz})$ are
$\lambda=1.8 \pm 0.6 \mathrm{~mm}$
in $\mathrm{SrF}_{2}: \mathrm{Bu}^{2+}$;
$\lambda=0.7-1 \mathrm{~mm}$ in $\mathrm{LaP}_{3}: \mathrm{Er}^{3+}$
$\lambda=0.2-0.4 \mathrm{~mm}$
in $\mathrm{CaF}_{2}: \mathrm{Fr}^{3+}$

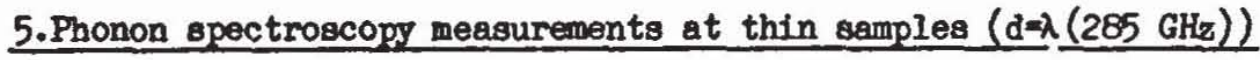

By reducing the sample thickness to the value of mean free path of $285 \mathrm{GHz}$ phonons the resonance structure at $21.2 \mathrm{~cm}^{-1}$ hardly detectable at the thick $\mathrm{CaP}_{2}$ : $\mathrm{Er}^{3}$ sample (see 2.) could now be well resolved (Fig.3 a ). Fig.3 b shows the high resolution phonon absorption spectrum of this resonance $(\Delta v=5.2 \mathrm{GHz})$.

An additional signal modification can be seen at $30 \mathrm{~cm}^{-1}$ (b) with less intensity. This absorption can be ascribed to respective $\mathrm{Er}^{3}$ crystalline field transitions already known from PIR-measurements (see 1.).
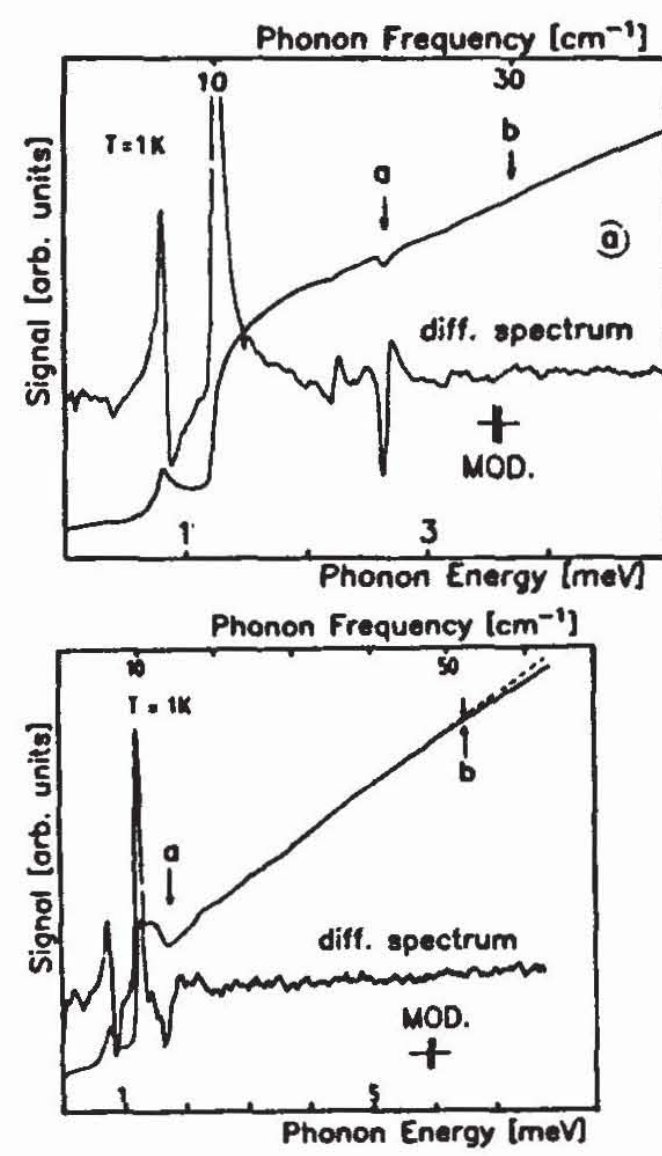

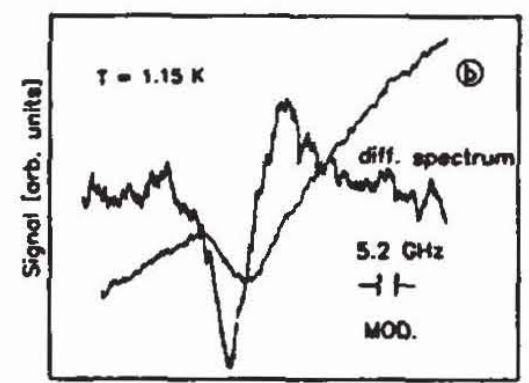

Fig.3 Phonon sopsorption epectrum of $\mathrm{CaP}_{2}: \mathrm{Er}^{3+} ; \mathrm{d}=300 \mu \mathrm{m}$

\section{$\mathrm{Fig}_{\mathrm{g}} 4$}

Phonon absorption spectrum of $\mathrm{LaP}_{3}: \mathrm{Br}^{3}$ $\mathrm{d}=1 \mathrm{~mm}$

Phonon absorption measurements were also applied to appropriate thin $\mathrm{LaP}_{3}: \mathrm{Er}^{3+}$ samples. Fis. 4 shows the related spectrum to a $d=1$ mn thick sample.

At $14.2 \mathrm{~cm}^{-1}$ a deep absorption line was found not visible in FIR-measurements $(a)$. This line so far could not be identified. For frequencies higher than $52 \mathrm{~cm}^{-1}$ a sienal reduction is observed (b). This can be explained by the frequency limit of the TA-branches in the phonon dispersion relation of $\mathrm{LaP}_{3}$. Phonons with frequencies higher than this limit cannot propegate in the sample.
[1] Ward/Clayman
21 Hadnt/Strimer
3] Bron, Keilmann
[4] Bisfeld, Renk
[5] Klemens
J. Phys. C Solid State Phys. Vol.8, p 872 (1975)
Phys. Rev. B; 5,11, 4609 (1972)
Phys. Rev. B 12, 2: 2496 (1975)
Int. Conf. in Phonon Scatterins, Brown University
Providence 1979
Proc. Phys. Soc. 68, 12A, 73 (1955) 